RACAR : Revue d'art canadienne

Canadian Art Review

RACAR

Ross A.C. Fox, Quebec and Related Silver at The Detroit

Institute of Arts. Detroit, Wayne State University Press, 1978,

174 p., 109 illus., $\$ 12.00$

\title{
Sylvio Normand
}

Volume 7, numéro 1-2, 1980

URI : https://id.erudit.org/iderudit/1076887ar

DOI : https://doi.org/10.7202/1076887ar

Aller au sommaire du numéro

\section{Éditeur(s)}

UAAC-AAUC (University Art Association of Canada | Association d'art des universités du Canada)

\section{ISSN}

0315-9906 (imprimé)

1918-4778 (numérique)

Découvrir la revue

Citer ce compte rendu

Normand, S. (1980). Compte rendu de [Ross A.C. Fox, Quebec and Related Silver at The Detroit Institute of Arts. Detroit, Wayne State University Press, 1978,

174 p., 109 illus., \$12.00]. RACAR : Revue d'art canadienne / Canadian Art Review, 7(1-2), 126-126. https://doi.org/10.7202/1076887ar

Tous droits réservés (C) UAAC-AAUC (University Art Association of Canada | Association d'art des universités du Canada), 1981
Ce document est protégé par la loi sur le droit d'auteur. L'utilisation des services d'Érudit (y compris la reproduction) est assujettie à sa politique d'utilisation que vous pouvez consulter en ligne.

https://apropos.erudit.org/fr/usagers/politique-dutilisation/ 
ROSS A.C. Fox Quebec and Related Silver at The Detroit Institute of Arts. Detroit, Wayne State University Press, 1978, 174 p., 109 illus., $\$ 12.00$.

Le volume de R.A.C. Fox présente, comme son titre l'indique, la collection d'orfevrerie québécoise du Detroit Institute of Arts. Le catalogue est précédé d'une introduction ( $p$. 1 3-19). Brièvement l'auteur situe la place de l'orfèvrerie dans la société d'avant et d'après la Conquête, présente les principaux orfèvres de Québec et de Montréal en insistant sur leur lieu d'origine et les liens qui les unissent, et traite des influences stylistiques étrangères qui marquèrent l'orfevrerie québécoise.

La collection du Detroit comprend 47 pièces. Les quatre premières sont des œuvres anonymes importées de France (cat. 1-4), la suivante, sans poinçon, a été façonnée soit en France soit au Québec (cat. 5), et les autres sont issues d'ateliers québécois. Le Musée possède une collection qui donne une excellente idée de la production québécoise, même si les deux grands orfèvres IgnaceFrançois Delzenne et François Ranvoyzé n'y sont pas représentés. Outre les œuvres des principaux orfèvres de Québec et de Montréal, la collection rassemble des pièces d'orfèvres qui travaillèrent à Detroit.

Le catalogue a été rédigé avec beaucoup de minutie. Fox s'est prêté à une étude approfondie des poinçons et a retracé, à l'aide des photographies prises par Gérard Morisset (Fonds Morisset, Inventaire des biens culturels, Québec), la provenance de presque tous les vases liturgiques. Acquises récemment pour la plupart, ces pièces ont malgré tout fait l'objet de publications et d'expositions. Toutes sont décrites avec exactitude. Des commentaires, notamment sur le style et l'attribution, suivent la présentation technique de chacune d'elles.

Les photographies des œuvres de cette collection ont l'avantage de présenter le profil des vases, ces prises de vue facilitant l'étude des formes. Tous les poinçons, même

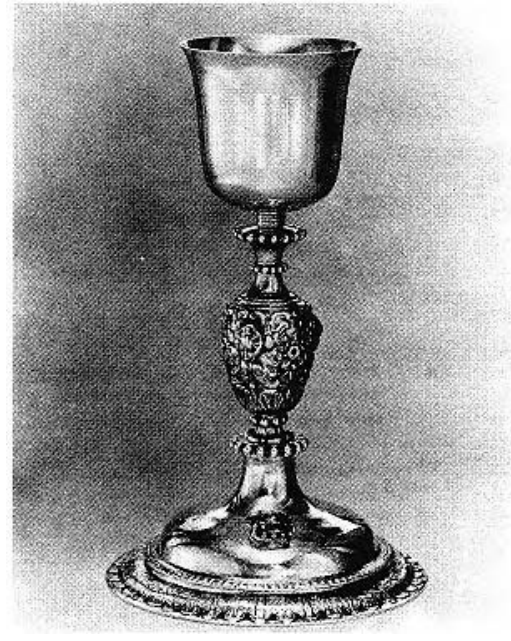

FIGURE 1. Anonyme (France), Calice. Fox, p. $25, \mathrm{n}^{0} 2$.

ceux remis en question, sont photographiés; il s'agit là d'une excellente initiative.

Une courte biographie précède la présentation des œuvres de chaque orfèvre. L'auteur a rédigé les biographies des orfèvres les plus connus à partir de publications et principalement des ouvrages de Traquair, Langdon et Derome. Les écrits des deux premiers auteurs comportent certaines faiblesses que l'on retrouve à l'intérieur de quelques biographies. Signalons que pour François Sasseville, il eût été avantageux d'utiliser la biographie rédigée par Jean Trudel pour le tome Ix du Dictionnaire biographique $d u$ Canada. Celles des orfèvres québécois qui travaillèrent à Detroit ont l'intérêt d'être souvent rédigées à partir de documents inédits.

Certaines pièces du catalogue ont particulièrement attiré notre attention, notamment à cause de leur poinçon. Un calice (cat. 2, Fig. 1) et deux assiettes identiques (cat. 3-4), marqués de poinçons québécois à l'authenticité douteuse, ont été prudemment attribués à des ateliers français. Les poinçons de Paul Lambert dit Saint-Paul et d'Ignace-François Landron sur l'assiette $\mathrm{n}^{\circ} \quad 3$ sont des variantes jusqu'ici inconnues; le fait qu'elles se retrouvent toutes les deux sur une même pièce laisse sceptique. Le calice $n^{0} 2$ avait antérieurement été attribué par Fox à François Ranvoyzé à cause de son poinçon constitué des lettres "F.R. " dans une oriflamme. Cette marque n'est toutefois semblable à aucun des nombreux autres poinçons répertoriés de cet orfèvre; cela a éveillé les soupçons de l'auteur et l'a forcé à reconsidérer sa première attribution. Un calice français inédit, conservé au Collège de Sainte-Anne-de-laPocatière, est d'un style très près de celui de Detroit. Trois autres pièces, d'origine québécoise cette fois, sont également marquées d'un poinçon possiblement faux (cat. 27 , 34 et $3^{8}$ ). Toutes ces incertitudes montrent de façon manifeste notre méconnaissance des variantes des différents poinçons des orfèvres postérieurs à la Conquête.

Deux ciboires de la période de la Nouvelle-France, l'un de l'orfevre parisien Guillaume Loir (cat. 16) et l'autre de l'orfevre Jean-François Landron (cat. 31 ) ont été partiellement restaurés par Robert Cruickshank vers 1790 . Bien que le second vase ne soit pas marqué du poinçon de Landron, Fox l'attribue à celui-ci à la suite de recoupements stylistiques avec d'autres vases de l'orfevire.

L'étude des ustensiles et de l'orfèvrerie de traite n'a pas été négligée. Ces pièces formaient à certaines époques une part importante de la production des orfèvres.

Deux appendices complètent le catalogue. Le premier porte sur l'importance des inventaires pour l'étude des types et de la quantité d'argenterie possédée par les individus et les Fabriques (p. 151-152). Le second présente les résultats d'une analyse de la composition métallique de 39 des 47 pièces de la collection.

Le catalogue de Fox est remarquable à tous les points de vue. L'auteur a su présenter de façon impeccable chacune des pièces et tirer le maximum de la documentation existante. La publication de la collection d'orfèvrerie québécoise de Detroit devrait inciter d'autres institutions et d'autres chercheurs à s'intéresser à ce secteur important de notre patrimoine qui, n'eut été du travil acharné de quelques individus passionnés, aurait été oublié depuis longtemps.

SYLVIO NORMAND Université Laval 